\title{
Commentary \\ Nebulised heparin: a new approach to the treatment of acute lung injury? \\ Peter M Suter
}

Centre Médical Universitaire, University of Geneva, CH-1211 Genève 4, Switzerland

Corresponding author: Peter M Suter, Peter.Suter@medecine.unige.ch

Published: 25 July 2008

This article is online at http://ccforum.com/content/12/4/170

(c) 2008 BioMed Central Ltd

See related research by Dixon et al., http://ccforum.com/content/12/3/R64
Critical Care 2008, 12:170 (doi:10.1186/cc6947)

this therapy did not cause significant changes in the ratio of arterial oxygen partial pressure $\left(\mathrm{PaO}_{2}\right)$ to inspired oxygen fraction $\left(\mathrm{FiO}_{2}\right)$, dead space or compliance. However, a trend for an increasing systemic anticoagulant effect with higher doses was observed.

The potential of airways and alveoli to absorb particles and chemical substances is impressive. The layer of liquid and surfactant covering the epithelial cells is continuous and offers relatively uniform diffusion possibilities. Inhaled particles can be observed submersed in the aqueous lining layer and adjacent to epithelial cells [2]. This allows interaction with these cells as well as diffusion through them into interstitial space and vascular and alveolar structures.

ALI seems an appropriate situation in which to consider application of an anticoagulant substance by the tracheobronchial route. This disease is characterized by typical pulmonary parenchymal changes, including marked inflammation, interstitial edema, microvascular thrombosis, alveolar fibrin deposition and fluid accumulation [3]. It has been shown, on one hand, that pulmonary inflammation can cause local disturbances in fibrin turnover; and on the other hand, it is known that an intra-alveolar pro-coagulant state with increased fibrin deposition and limited breakdown may enhance inflammatory changes [4-6]. The role of platelets and leukocytes, activated by these coagulation disorders, must also be stressed. Given the extensive crosstalk between coagulation and inflammation, targeting pulmonary coagulopathy may influence the local inflammatory response and, thereby, the clinical course of ALI [6]. As suggested by a number of experimental and clinical studies, heparin has anticoagulant and fibrinolytic properties as well as anti-inflammatory effects. Given by nebulisation, this substance had positive effects in animal models of ALI or lung fibrosis $[7,8]$.

$A L I=$ acute lung injury. 
The translation of a potentially beneficial effect of inhaled heparin in experimental models of ALI to clinical practice has not yet been achieved; important additional work remains to be done. The following questions need to be answered. As the pro-coagulant state in the alveolar space begins in the early phases of ALI, how can it be assessed in order to initiate heparin administration as rapidly as necessary? How can dosage of the drug be titrated to achieve maximal local effects without the risk of systemic complications? What is the adequate duration of this therapy? Does the underlying cause of ALI make any difference with regard to this approach? Ultimately, randomized controlled trials will provide the data necessary to determine its clinical utility.

ALI represents a complex syndrome with different possible causes and origins, but also involves patients with complex conditions: 'standard' care has to be defined in detail in such situations, and rigorous control of physiological variables as well as therapeutic modalities is of the outmost importance [9]. The use of 'treatment bundles' could be a further necessary step in the direction of optimal patient management in this disease [10].

\section{Competing interests}

The author declares that he has no competing interests.

\section{References}

1. Dixon B, Santamaria JD, Campbell DJ: A phase 1 trial of nebulised heparin in acute lung injury. Crit Care 2008, 12:R64.

2. Geiser M, Schürch S, Gehr P: Influence of surface chemistry and topography of particles on their immersion into the lung's surface-lining layer. J Appl Physio/ 2003, 94:1793-1801.

3. Ware LB, Matthay MA: The acute respiratory distress syndrome. N Engl J Med 2000, 342:1334-1349.

4. Schultz MJ, Millo J, Levi M, Hack CE, Weverling GJ, Garrard CS, Poll T: Local activation of coagulation and inhibition of fibrinolysis in the lung during ventilator associated pneumonia. Thorax 2004, 59:130-135.

5. Gropper MA, Wiener-Kronish J: The epithelium in acute lung injury/acute respiratory distress syndrome. Curr Opin Crit Care 2008, 14:11-15.

6. Hofstra JJH, Juffermans NP, Schultz MJ, Zweers MM: Pulmonary coagulopathy as a new target in lung injury - a review of available pre-clinical models. Curr Med Chem 2008, 15:288-295.

7. Murakami K, McGuire R, Cox RA, Jodoin JM, Bjertnaes LJ, Katahira J, Traber LD, Schmalstieg FC, Hawkins HK, Herndon DN, Traber DL: Heparin nebulization attenuates acute lung injury in sepsis following smoke inhalation in sheep. Shock 2002, 18:236-241.

8. Gunther A, Lubke N, Ermert M, Schermuly RT, Weissmann N, Breithecker A, Markart P, Ruppert C, Quanz K, Ermert L, Grimminger $F$, Seeger W: Prevention of bleomycin-induced lung fibrosis by aerosolization of heparin or urokinase in rabbits. Am J Respir Crit Care Med 2003, 168:1358-1365.

9. Chiche JD, Derek CA: Testing protocols in the intensive care unit: complex trials of complex interventions for complex patients. JAMA 2008, 299:693-695.

10. Kaisers $U$, Busch $T$ : Improving survival in acute lung injury: is there a role for treatment bundles? Crit Care Med 2007, 35: 10. 